\section{Detection of Elizabethkingia spp. in Culicoides Biting Midges, Australia}

\section{Peter T. Mee, Stacey E. Lynch, Peter J. Walker, Lorna Melville, Jean-Bernard Duchemin}

Author affiliations: The University of Melbourne, Parkville, Victoria, Australia (P.T. Mee); Agriculture Victoria, AgriBio, Bundoora, Victoria, Australia (P.T. Mee, S.E. Lynch); Commonwealth Scientific Industrial Research Organization, Geelong, Victoria, Australia (P.T. Mee, P.J. Walker. J.-B. Duchemin); University of Queensland, St Lucia, Queensland, Australia (P.J. Walker); Department of Primary Industry and Fisheries, Berrimah, Northern Territory, Australia (L. Melville)

DOI: https://doi.org/10.3201/eid2308.161565

The bacterial pathogen Elizabethkingia is known to exist in certain species of mosquito but was unknown in other arthropods. We report the detection and identification of Elizabethkingia in species of Culicoides biting midge in Australia, raising the possibility of bacterial transmission via this species.

$\mathrm{B}$ acteria in the genus Elizabethkingia (formerly Chryseobacterium or Flavobacterium) are gram-negative bacilli that occur globally in water sources including rivers, reservoirs, and soils. In recent years, 3 medically important species in this genus, E. meningoseptica, E. anophelis, and E. mirico$l a$, have been recognized as the cause of emerging nosocomial infections, neonatal sepsis, and infections in immunocompromised persons. Outbreaks and infections have occurred globally, with cases reported in the Central African Republic; Singapore; Hong Kong, China (1); India; Australia; and the United States. Infection by any of the 3 species can cause septicemia, with a recorded mortality rate of $23.5 \%(1-3)$.

Originally, E. meningoseptica was thought to be the causative agent of most Elizabethkingia infections. However, E. anophelis has recently been implicated as the more likely cause and as the primary species associated with bacteremia (1). Isolated from Anopheles gambiae mosquitoes in 2011 (4), E. anophelis has a relatively high occurrence
$(68 \%)$ in field-collected mosquitoes (5) and has been identified in Aedes aegypti and An. stephensi mosquitoes $(6,7)$, with transmission between mosquitoes by vertical, horizontal, and transstadial modes $(6,7)$. Occurrence of Elizabethkingia in other arthropods has not been reported.

Culicoides biting midges are classified in the family Ceratopogonidae in the order Diptera. These arthropods are found around the world and are capable of transmitting pathogens (mainly viral or filarial but also bacterial) affecting birds, livestock, and humans. In Australia, there are 78 described and 61 undescribed species of Culicoides midges. We investigated the presence of Elizabethkingia in Culicoides midges in Australia.

In summer 2013, we collected 66 Culicoides individuals in Australia from 3 locations (Table) using light traps: 24 C. victoriae, 21 C. multimaculatus, and 21 C. brevitarsis. We examined them for the presence of Elizabethkingia using 16S rRNA amplicon sequencing. Culicoides were collected from 3 locations (Table) using light traps. The midges were identified to species morphologically from homogenized females at CSIRO, Geelong, Victoria, Australia, before DNA extraction using a QIAGEN blood and tissue kit (QIAGEN, Valencia, California, USA). Culicoides species identification was confirmed by sequencing the COI gene (8).

We amplified the hypervariable region V3-V4 of the 16S rRNA (422 bp) using PCR primers (S-D-Bact-0341-b-S-17/SD-Bact-0785-a-A-21) (9), following a modified 16S MiSeq protocol and barcoded samples before sequencing on a MiSeq (Illumina, Victoria, British Columbia, Canada). Two negative controls were included throughout the sequencing methodology to ensure no contamination. We analyzed data using the Quantitative Insights into Microbial Ecology pipeline (10) with reference to Greengenes database. To confirm Elizabethkingia species, we used primers forward 5'-ATCTTCATGGAAGGAGAGC- $3^{\prime}$ and reverse 5'-GTACCAACACTTACCCCTAA- $3^{\prime}$ to amplify $670 \mathrm{bp}$ of the gene encoding the subunit B protein of the DNA gyrase ( $g y r B)$. Amplicons were purified and then sequenced using a capillary Sanger method.

Sequencing analysis identified a total of $2,717,401$ operational taxonomic units across the 66 samples, after all quality trimming procedures and removal of chimeras. Based on the 16S rRNA (GenBank accession no. KX870017) amplicon sequence ( $>280$ times coverage), we

\begin{tabular}{|c|c|c|c|c|c|}
\hline Culicoides species & Collection location & $\begin{array}{c}\text { Collection } \\
\text { coordinates }\end{array}$ & $\begin{array}{c}\text { \% Infected with } \\
\text { Elizabethkingia (no. } \\
\text { infected/no. collected) }\end{array}$ & $\begin{array}{c}\text { Average no. } \\
\text { Elizabethkingia reads } \\
\text { per individual }(95 \% \mathrm{Cl})\end{array}$ & $\begin{array}{c}\text { Average } \% \\
\text { Elizabethkingia reads to } \\
\text { bacterial reads }(95 \% \mathrm{Cl})\end{array}$ \\
\hline C. brevitarsis & $\begin{array}{c}\text { Beatrice Hill, } \\
\text { Northern Territory }\end{array}$ & $\begin{array}{l}12^{\circ} 39^{\prime} \mathrm{S} \\
131^{\circ} 19^{\prime} \mathrm{E}\end{array}$ & $71(15 / 21)$ & $1,419(724-2,113)$ & $0.075(0.05-0.1)$ \\
\hline C. multimaculatus & $\begin{array}{c}\text { Lake Wellington, } \\
\text { Victoria }\end{array}$ & $\begin{array}{l}38^{\circ} 23^{\prime} \mathrm{S} \\
147^{\circ} 21^{\prime} \mathrm{E}\end{array}$ & $0(0 / 21)$ & NA & NA \\
\hline C. victoriae & $\begin{array}{c}\text { Grampians, } \\
\text { Victoria }\end{array}$ & $\begin{array}{l}38^{\circ} 08^{\prime} \mathrm{S} \\
142^{\circ} 12^{\prime} \mathrm{E}\end{array}$ & $0(0 / 24)$ & NA & NA \\
\hline
\end{tabular}

${ }^{\star} \mathrm{NA}$, not applicable. 
determined that Elizabethkingia infected only C. brevitarsis midges (Table). We did not detect Elizabethkingia in negative control samples.

Elizabethkingia sequences had 100\% nucleotide identity among the 15 C. brevitarsis individuals and high sequence identity to E. anophelis $(99.05 \%-99.29 \%), E$. meningoseptica $(98.34 \%-100 \%)$, and E. miricola $(99.76 \%)$ based on sequences obtained from GenBank. However, we were unable to identify the exact strain based on $16 \mathrm{~S}$ rRNA alone. We successfully amplified Elizabethkingia gyrB (GenBank accession no. KX870018) and concatenated sequences with the $16 \mathrm{~S}$ rRNA region, forming a 1,072-bp amplicon. The phylogenetic analysis confirmed $E$. anophelis as the closest to the species isolated from C. brevitarsis, with $95.8 \%$ identity across the 2 amplified gene regions.

The $C$. brevitarsis midge is a known vector of several pathogenic viruses in livestock of Australia. Of the many diverse Culicoides midge species, some transmit human pathogens; the close association of some species with humans suggests a need for a more detailed study.

Although we did not detect Elizabethkingia in C. victoriae or C. multimaculatus midges, this finding may be a result of differences in climate or ecosystem. Unlike mosquitoes that breed in water, the $C$. brevitarsis midge uses cow dung, so it is potentially isolated from environmental contamination of Elizabethkingia. Because Culicoides midges are widespread and can be displaced great distances by wind currents, the potential for them to transport the bacterium warrants further investigation.

The nature of the association between insects and Elizabethkingia is unknown. Mosquitoes have been reported to harbor Elizabethkingia, but it is unknown if they act as vectors or simply serve as reservoirs, symbionts, or environmental markers. One study investigating the possible role of mosquitoes as vectors of Elizabethkingia suggests that they act as reservoirs (3). Nevertheless, while the role of insects as vectors of infection remains unclear, the identification of Elizabethkingia in Culicoides midges is relevant to public health. The gyrB primers developed in this study allow more accurate diagnosis of Elizabethkingia species than a single gene classification.

Collection of $C$. victoriae was possible due to the Department of Sustainability and Environment permit number 10006587. Collection of C. multimaculatus was possible due to the Department of Health and Human Services-funded Victorian Arbovirus Disease Control Program.
Mr. Mee is a PhD student working on Culicoides in collaboration between the University of Melbourne and Commonwealth Scientific Industrial Research Organization Australian Animal Health Laboratory. He has studied insect vectors since 2010, primarily focusing on mosquitoes and biting midges, as well as the bacterial endosymbionts that influence them.

\section{References}

1. Lau SKP, Chow W-N, Foo C-H, Curreem SOT, Lo GC-S, Teng JLL, et al. Elizabethkingia anophelis bacteremia is associated with clinically significant infections and high mortality. Sci Rep. 2016;6:26045. http://dx.doi.org/10.1038/srep26045

2. Sarma S, Kumar N, Jha A, Baveja U, Sharma S. Elizabethkingia meningosepticum: an emerging cause of septicemia in critically ill patients. J Lab Physicians. 2011;3:62-3. http://dx.doi.org/ 10.4103/0974-2727.78575

3. Lau SKP, Wu AKL, Teng JLL, Tse H, Curreem SOT, Tsui SKW, et al. Evidence for Elizabethkingia anophelis transmission from mother to infant, Hong Kong. Emerg Infect Dis. 2015;21:232-41. http://dx.doi.org/10.3201/eid2102.140623

4. Kämpfer P, Matthews H, Glaeser SP, Martin K, Lodders N, Faye I. Elizabethkingia anophelis sp. nov., isolated from the midgut of the mosquito Anopheles gambiae. Int J Syst Evol Microbiol. 2011;61:2670-5. http://dx.doi.org/10.1099/ijs.0.026393-0

5. Boissière A, Tchioffo MT, Bachar D, Abate L, Marie A, Nsango SE, et al. Midgut microbiota of the malaria mosquito vector Anopheles gambiae and interactions with Plasmodium falciparum infection. PLoS Pathog. 2012;8:e1002742. http://dx.doi.org/10.1371/ journal.ppat. 1002742

6. Coon KL, Vogel KJ, Brown MR, Strand MR. Mosquitoes rely on their gut microbiota for development. Mol Ecol. 2014;23:2727-39. http://dx.doi.org/10.1111/mec.12771

7. Ngwa CJ, Glöckner V, Abdelmohsen UR, Scheuermayer M, Fischer R, Hentschel U, et al. 16S rRNA gene-based identification of Elizabethkingia meningoseptica (Flavobacteriales: Flavobacteriaceae) as a dominant midgut bacterium of the Asian malaria vector Anopheles stephensi (Dipteria: Culicidae) with antimicrobial activities. J Med Entomol. 2013;50:404-14. http://dx.doi.org/10.1603/ME12180

8. Mee PT, Weeks AR, Walker PJ, Hoffmann AA, Duchemin J-B. Detection of low-level Cardinium and Wolbachia infections in Culicoides. Appl Environ Microbiol. 2015;81:6177-88. http://dx.doi.org/10.1128/AEM.01239-15

9. Klindworth A, Pruesse E, Schweer T, Peplies J, Quast C, Horn M, et al. Evaluation of general 16S ribosomal RNA gene PCR primers for classical and next-generation sequencing-based diversity studies. Nucleic Acids Res. 2013;41:e1. http://dx.doi.org/10.1093/nar/ gks808

10. Caporaso JG, Kuczynski J, Stombaugh J, Bittinger K, Bushman FD, Costello EK, et al. QIIME allows analysis of high-throughput community sequencing data. Nat Methods. 2010; 7:335-6

Address for correspondence: Peter T. Mee, Agriculture Victoria, AgriBio, Centre for AgriBioscience, Bundoora, Victoria, 3219, Australia; email: peter.mee@ecodev.vic.gov.au 